\title{
SSinteza
}

Impact of Internet on Business Activities

\section{UTICAJ INFORMACIONIH TEHNOLOGIJA NA MARKETING U TURIZMU BOSNE I HERCEGOVINE}

\author{
Biljana Rađenović Kozić \\ Univerzitet za poslovne studije, Banja luka, BIH
}

\begin{abstract}
:
Rad pod naslovom „Uticaj informacionih tehnologija na marketing u turizmu Bosne i Hercegovine" se bavi analizom stanja implementiranosti informacionih tehnologija u turizmu jedne konkretne turističke destinacije. U radu se jasno vidi koliki je značaj novih tehnologija u svim aspektima marketinga u turizmu. Kada se kaže u svim aspektima, u stvari se misli na aktivnosti od istraživanja tržišta, preko kreiranja marketing strategija, pa do samih integrisanih marketing komunikacija. Kroz istraživanje institucija i preduzeća turizma Bosne i Hercegovine, koje je realizovano metodom ispitivanja, u radu se dolazi do saznanja kako menadžeri institucija i preduzeća u turizmu, odabrane destinacije, gledaju na koristi od primjene informacionih tehnologija i koliko su one zaista implementirane u turizam Bosne i Hercegovine. Na bazi rezultata pomenutog istraživanja i teorije iz ove oblasti, konačno, izvode se smjernice za njihovu efikasniju primjenu.
\end{abstract}

\author{
Key words: \\ marketing u turizmu, \\ implementacija informacionih \\ tehnologija, \\ turistička destinacija, \\ Bosna i Hercegovina.
}

\section{UVOD}

Primjena informacionih tehnologija u ekonomiji pa samim tim i marketingu često se naziva informacionom ekonomijom ili novom ekonomijom. Savremene tendendencije, elektronsko tržište, novi principi marketinga i sl. svakako da su se odrazili i na turizam. Dakle, izmjene u poslovanju i specifičnosti tržišta 21.vijeka rezultovale su pojavom jednog novog pristupa marketingu, u literaturi često označen pojmom elektronski marketing ili $\mathrm{E}$ - marketing. Ako se E - marketing posmatra kao marketinški metod koji podrazumijeva korištenje elektronskih uređaja i/ili tehnologija baziranih na elektronici u cilju efikasnijeg ostvarenja marketing ciljeva, onda se može izvesti zaključak da je danas malo marketinških aktivnosti koje na neki način ne uključuju njihovo korištenje. Istina da turizam možda ne slijedi dosljedno te procese, već ih usložnjava. Ta složenost, proizilazi iz složenosti turističkog tržišta, turističkog proizvoda i svih manifestacija turizma. Proizilazi i iz potrebe koordinacije niza učesnika u stvaranju, kreiranju i isporuci turističkog proizvoda. Jer, ako E - marketing znači, promociju putem novih medija, prodaju, kreiranje novih proizvoda, uvezivanje sa partnerima, građenje dugoročnih odnosa, pomoć kod istraživanja tržišta, kreiranje baze podataka, pomoć u izgradnji imidža i još puno toga, onda je sve ovo primjenivo i važno i u turizmu 21. vijeka, uvažavajući sve njegove specifičnosti. Ili, bolje rečeno sve ovo je složenije i neophodno primjenjivati, ako se želi postati i ostati konkurentan na turističkom tržištu.
Zbog svega toga, danas možemo govoriti o $\mathrm{E}$ - turizmu i $\mathrm{E}$ - marketingu u turizmu. E - marketing u turizmu može da podrazumijeva marketing aktivnosti koje se obavljaju uz pomoć informacione i komunikacione tehnologije uposlene u kontekstu razvoja i funkcionisanja elektronskih tržišta, pri čemu postoji značajna uključenost turista, bilo na planu pretrage/zahtijeva za informacijama o destinaciji, cijenama itd, bilo kao izvora marketinških informacija o sebi, ponašanju, kupovini i sl. On ujedno podrazumijeva digitalizaciju svih procesa u marketingu turističkih destinacija i preduzeća. Pri tome, ovaj pojam ne mora nužno značiti da će kupovina biti nužno obavljena putem elektronske trgovine. Primjena E - marketinga u turizmu je više od obavljene kupovine. Važno je da postoji razmjena informacija sa potrošačima putem ovog tržišta, da je njihova uključenost izražena i da informacije dobijene tom uključenošću mogu biti od koristi marketing menadžmentu destinacije. Koliko je marketing turizma Bosne i Hercegovine zaista digitalizovao svoje aktivnosti i koliko zaista koristi E- marketing kao sredstvo za postizanje bolje konkurentske pozicije, osnovni je problem proučavanja ovog rada.

\section{E - MARKETING U TURIZMU}

Turizam ima mnogo karakteristika informacione i komunikacione ekonomije [1]. Novi pristup u ekonomiji izvršio je, između ostalog, i uticaj na unapređenje metodologija, organizacija i sadržaja strateških aktivnosti u mar- 
ketingu i rezultovao novim pricipima marketinga. Prema Kotleru i Keleru novi principi marketinga su [2]:

1. Organizacija po tržišnim segmentima

2. Težište na trajnoj vrijednosti za kupce

3. Gledanje na marketinške efekte, jednako kao i na finansijske

4. Težište na zadovoljavanju više grupa (stakeholders) zainteresovanih za uspjeh kompanije (u ovom slučaju destinacije)

5. Svi u kompaniji se bave marketingom

6. Marke se grade prema ukupnom ponašanju kompanije (destinacije)

7. Težište je na zadržavanju kupaca

8. Mjeri se vrijednost za kupca i kupčevu lojalnost

9. Obećaj manje a isporuči više

10. „Lanac vrijednosti“ je jedinica za analizu

Jasno je da novi principi nisu rezultat samo informacionih tehnologija već i promjena na tržištu, ali su one omogućile njihovu efikasniju realizaciju. Očigledno je da pridržavanje nekih od navedenih marketing principa u kreiranju strategije predstavljaju nove izazove, jer to znači da segmente treba mnogo detaljnije istraživati, definisati i kontinuirano pratiti, što zahtijeva adekvatnu informacionu podršku [3]. Informaciona podrška počevši od istaživanja potrošača i sopstvene pozicije na tržištu preko povezivanja sa partnerima pa do prodaje i promocije proizvoda je ono što daje sve veći uticaj E - marketinga na turističkom tržištu i neophodnost korištenja njegovih mogućnosti u unapređenju odnosa sa turistima i drugim interesnim grupama, te samim tim poboljšanja stanja u samoj destinaciji i njenog imidža. One, dakle, omogućuju menadžmentu turističke destinacije efikasniju komunikacija sa turistima, ali i informaciono uvezivanje sa partnerima, sa preduzećima turističke privrede, sa medijima i sl. Ovaj marketing, efikasnom primjenom, stvara preduslove upravo za ono što je bio najveći problem u upravljanju promocijom destinacije, a to je integracija i koordinacija.

E - marketing, svakako, ima mnoge manifeste, ali sa aspekta postavljene problematike rada, nemoguće je a ne dati poseban značaj Internetu. Važno je naglasiti da Internet nikako nije isto što i $\mathrm{E}$ - marketing. Naprotiv, on je mnogo uži pojam, koji između niza ostalih elemenata, gradi E- marketing. Ono što je neosporno je činjenica da Internet neprestano raste i da njegova ekspanzija obilježava poslovanje svih privrednih grana, a naročito turizma zbog prostorne udaljenosti receptivnog i emitivnog tržišta. Upravo zbog te udaljenosti www (World Web Wide) postaje veoma važan kada je rijeć o marketingu turističke destinacije. Na promjenama u organizaciji promocije na nivou destinacije je svakako World Wide Web (www), ostavio najviše traga. Pojavom $w w w$ - a pristup promociji, koji je važio desetinama godina, naglo je doživio promjene. Posljednjih godina, zahvaljujući njemu Internet je postao ključni način promocije država, gradova i turističkih destinacija širom svijeta [4]. Može se identifikovati pet glavnih tipova On line prisustva ili komponenti mogućih kao dio web site - a [5]:

- Transakcioni web site - omogućava kupovinu destinacijskih integrisanih proizvoda, ovim putem.
- Web site orjentisan prema uslugama, koji gradi odnose - daje informacije da bi gradio odnose sa turistima i inicirao na kupovinu. Ne mora i najčešće i nema mogućnost on line kupovine. Njime se generiše dvosmjerna komunikacija sa turistima i razmjena informacija.

- Site koji gradi brend - Nudi turistima iskustvo i doživljaj kako bi se podržao brend i imidž. Ne nudi kupovinu, već se razvija on line doživljaj brenda i imidža. Najvažniji su za NTO i druge turističke organizacije.

- Portal ili medijski web site - omogućava posrednicima (turističkim agencijama i drugim posrednicima) da daju informacije i komuniciraju sa turistima.

- Društvene mreže ili web site zajednice - omogućavaju interakciju različitih grupa potrošača. Tipične interakcije su postavljanje komentara i odgovora, slanje poruka, ocjenjivanje sadržaja i sl. Na taj način indirektno utču na imidž.

\section{INFORMACIONI SISTEMI KAO OSNOVA PRIMJENE E - MARKETINGA U TURIZMU}

E - marketing posmatran kroz Internet, baze podataka ili neke druge vidove njegovog manifesta, nemoguće je sagledati bez poznavanja informacionih sistema u turizmu, kao preduslova za njegovo fukcionisanje. Informacione sisteme u turizmu možemo posmatrati sa više aspekata. Jedan od njih je sa aspekta potrošača, gdje savremene tehnologije preuzimaju ulogu podrške proizvodu u plasiranju na tržište putem savremenih kanala prodaje ili promovisanja proizvoda putem tih kanala, obezbjeđujući da je proizvod dostupniji turisti. Drugi pristup je sa stanovišta preduzeća turističke privrede jer im ove tehnologije omogućavaju međusobno povezivanje i lakši plasman sopstvenih usluga na udaljena emitivna tržišta. Posmatrano iz ugla planiranja i razvoja destinacije i njenog imidža, odnosno kreatora strategija, informacione tehnologije se posmatraju kao podrška kontinuiranom istraživanju tržišta i osnova za lakše prikupljanje podataka koji će biti od suštinskog značaja za uspjeh na tržištu. Kako sve više na značaju dobija strategija zadržavanja kupaca i postizanja njihove lojalnosti, informacione tehnologije dobijaju na značaju jer predstavljaju suštinsku podršku ovoj marketing strategiji. Informaciona podrška omogućava stvaranje takve baze podataka o kupcima koja je toliko detaljna i aktuelna da omogućava praćenje ponašanja svakog pojedinog kupca i prilagođavanje njegovim specifičnim željama i potrebama. Ovakve baze podataka najprije su počele da se koriste u velikim hotelskim lancima i avio kompanijama. Značaj korištenja ovakvih tehnologija u upravljanju E - marketingom u turizmu Bosne i Hercegovine je neosporan i može da se ogleda u:

- prikupljanju informacija o potencijalnim turistima

- definisanju segmenata na osnovu informacija dobijenih istraživanjem tržišta

- kontinuiranom praćenju stvarnih turista po svakom segmentu 
- preuzimanju podataka od preduzeća turističke privrede

- stvaranju aktivne baze o svakom turisti i njegovim karakteristikama

- olakšanom prilagođavanju ponude i komunikacije

Pored ovakve analize informacionih tehnologija, koja je izuzetno važna zbog stanja u kome se nalazi turizam Bosne i Hercegovine, ipak ne može da se zanemari ni njihov značaj i aspekti podrške promociji i plasmanu proizvoda te povezivanja sa kupcima (Kompjuterski rezervacioni sistemi; Destinacijski marketinški sistemi; Database marketing; Ekspertni sistemi; Internet itd.), o čemu je više riječi bilo u prethodnom poglavlju kroz analizu uticaja Interneta. Očito je, dakle, da je razvoj informacionih tehnologija na turističkom tržištu pratio razvoj u svim drugim oblastima turizma. Destinacije i preduzeća, koja imaju svijest o neophodnosti informacionih tehnologija, ostvaruju bolju poziciju na tržištu. Shodno tome, razvoj novih tehnologija imaju neosporan uticaj i na promjene u marketing strategiji, a savremena marketing strategija bolje razumije tržište. Većina kompanija (destinacija) je primjenom ovih tehnologija uspjela da veže potrošače za sebe i ostvari veće profite i tržišnu vrijednost, a time i da utiče pozitivno na sliku o sebi [6]. Sasvim je jasno da turistička destinacija, koja želi da se uključi na turističko tržište, mora primjenjivati principe novih tehnologija. Ta primjena je nužna za uspjeh marketing strategije i pozicije Bosne i Hercegovine na tržištu. Ove tehnologije mogu služiti višestruko u ostvarivanju tih ciljeva:

- kao pomoć javnim ustanovama za lakše organizovanje turističke politike

- kao servis preduzećima i institucijama

- kao poseban vid uspostavljanja komunikacija sa turistima i pridobijanje istih

- kao savremen kanal distribucije

- kao veza sa partnerima i okruženjem i sl.

Sa stanovišta upravljanja E-marketingom u turizmu Bosne i Hercegovine neophodno je mjerama edukacije i propisa od strane institucija turizma, uputiti preduzeća na značaj formiranja sopstvenih baza i razmjenu podataka, kao prve faze u implementaciji savremenih tokova u turizam ove destinacije. Saznanja ko su naši turisti, kako se ponašaju, da li su zadovoljni i ako nisu zašto nisu, odgovara li ponuda onoj koju su upoznali putem promocije, kako su saznali za destinaciju, kakva je slika destinacije u njihovim glavama itd., moraju biti osnova za korekcije i prilagođavanje ponude. Statistički podatak npr. da je ove godine broj turista manji nego prethodne ne znači ništa ako ne znamo razlog zašto nam se turisti nisu vratili. Formirati bazu podataka u koju će se unositi svi važni podaci o turistima, njihovim zadovoljstvima i nezadovoljstvima, najveća su prednost informacionih tehnologija za posmatranu destinaciju, ne umanjujući značaj ovih tehnologija u koordinaciji između aktera i u promociji. U smislu organizovanja jedinstvene ponude destinacije, Turističko udruženje Bosne i Hercegovine, preko sistema podrške drugih državnih organa može postati inicijator uključenja preduzeća u kompjuterske rezervacione sisteme ili formiranja sopstvenih na lokalnom, regionalnom ili dr- žavnom nivou. Kao podrška razvoju imidža destinacije, formiranje ekspertnog sistema je domen o kome treba intenzivno razmišljati. Destinacijski marketinški sistem koji će objediniti sve potrebne informacije mora biti nosilac značaja ovih tehnologija za ostvarenje lakše komunikacije sa turistima. Gotovo jedini vid ovih tehnologija koji se primjenjuje na nivou posmatrane destinacije je Internet $\mathrm{i}$ to preko web stranica, koje ne podržavaju jednu organizovanu promotivnu aktivnost već daju osnovne informacije i međusobno su često neusaglašene. O informacionim tehnologijama u smislu njihove uloge u koordinaciji, teško se može govoriti. Shodo tome, u turizmu Bosne i Hercegovine ne možemo govoriti o dosljednoj primjeni E- marketinga, već više o sporadičnom djelovanju. Da bi se ova teza potvrdila i dale smjernice za poboljšanje, sprovedeno je i primarno istraživanje.

\section{ANALIZA REZULTATA PRIMARNIH ISTRAŽıVANJA}

Kako bi se, konkretno sagledala ova problematika u Bosni i Hercegovini (BIH), realizovanoje istraživanje. Primarno istraživanje je obuhvatilo ispitivanje 50 preduzeća turističke privrede i 32 institucije turizma u BIH, uz pomoć ankete koja je posebno bila prilagođena svakoj od ovih grupa. Ravnomjerno su obuhvaćena i preduzeća i institucije (Turističke organizacije i Turističke zajednice) sa terirorije Republike Srpske i Federacija Bosne i Hercegovine. Odabran je namjerni uzorak, sa ciljem da se ispitaju oni koji direktno mogu uticati na proces upravljanja marketingom u turizmu BIH. Cilj ispitivanja je bio da se ispita koliko oni koji upravljaju bilo turističkim prduzećima, bilo institucijama turizma vide značaj informacionih tehnologija u efikasnom upravljanju marketingom u turizmu. Kako je u radu ovog obima nemoguće detaljno predstaviti uzorak i instrumente, oni će biti predstavljeni tako da doprinose razumijevanju rezultata istraživanja. Pored toga biće predstavljene deskriptivne statističke mjere i regresiona analiza, bazi čega će se formulisati zaključci.

Kada je riječ o preduzećima, za ispitivanje iskustva i stavova vezanih implementaciju i doprinos informacionih tehnologija: zaštiti potrošača, konkurentskoj poziciji, asortimanu, pogodnostima i podsticajima za potrošače, stanju integrisanih marketing komunikacija te stanju prodajnog osoblja konstruisana je i korištena skala Spoljni i unutrašnji elementi marketinga. Skala se sastoji od pedeset i jedne stavke odnosno šest subskala. Skala procjene se sastoji od pet stepeni: 1 = potpuno nevažno, $2=$ uglavnom nevažno, 3 = ni važno ni nevažno, $4=$ uglavnom važno i 5 = veoma važno. Konačan skor za svaku subskalu se formira kao aritmetička sredina gdje se teorijski raspon rezultata kreće od 1 do 5 . Od pedeset ispitanika dobijeno je 100\% odgovora, dakle na sva pitanja su odgovorili svi ispitanici. Sve subskle pokazale su zadovoljavajuću pouzdanost tipa unutrašnje konzistencije. Kronbah alfa pokazuje sljedeće vrijednosti: 1 .Subskala zaštita potrošača alfa $=.87,2$. Subskala konkurencija alfa $=.40,3$. Subskala asortiman alfa $=.85,4$. Subskala pogodnosti i poticaji za potrošače alfa $=$ $.78,5$. Subskala integrisane marketing komunikacije alfa $=.79 \mathrm{i} 6$. Subskala prodajno osoblje alfa $=.90$. Distribucija 
rezultata po skalama je predstavljena u Tabeli 1. redom kojim su ovdje navedene, gdje je Subskala zaštita potrošača označena kao 1.S , subskala konkurencija označena u tabeli kao 2.S i tako sve do subskale prodajno osoblje koja je označena kao 6.S.

Tabela 1 Mjere centralne tendencije, mjere varijabilnosti, mjere oblika distribucije i vrijednosti testiranja normalnosti distribucije

\begin{tabular}{|c|c|c|c|c|c|c|c|c|}
\hline $\mathrm{M}$ & $\mathrm{N}$ & $\mathrm{SD}$ & $\mathrm{Min}$ & $\mathrm{Max}$ & Skewen & Kurt. & $\mathrm{K}-\mathrm{Zz}$ & Sig. \\
\hline 1. S 50 & 4.24 & .50 & 3 & 5 & -.694 & .014 & .143 & .012 \\
\hline 2.5 50 & 3.48 & .34 & 3 & 4.33 & 1.195 & .655 & .246 & .000 \\
\hline 3. S 50 & 3.72 & .66 & 2.33 & 5 & -.153 & -.912 & .144 & .011 \\
\hline 4.5 50 & 3.52 & .67 & 2 & 4.71 & -.464 & -.320 & .120 & .068 \\
\hline 5.S 50 & 3.46 & .45 & 2.53 & 4.26 & -.472 & -.535 & .129 & .036 \\
\hline 6.5 50 & 3.98 & .65 & 2.33 & 5 & -.632 & .253 & .131 & .032 \\
\hline
\end{tabular}

Dobijena distribucija rezultata ispitanika na skali pogodnosti i podsticaji za potrošače/turiste ne odstupa značajno od normalne distribucije, dok dobijene distribucije rezultata ispitanika na skalama zaštita potrošača/turista, konkurencija, asotriman, integrisane marketing komunikcije i prodajno osoblje značajno odstupaju od normalne distribucije što potvrđuju rezultati Kolmogorov-Smirnovog testa datih u tabeli. Dobijene distribucije rezultata ispitanika na skalama asortiman i integrisane markting komunikacije su umjereno negativno asimetrične, što znači da su rezultati ispitanika umjereno pomjereni prema višim vrijednostima. Na skalama zaštita potrošača i prodajno osoblje su znatno negativno asimetrične, što znači da su rezultati ispitanika znatno pomjereni prema višim vrijednostima, dok su na skali konkurencija znatno pozitivno asimetrični, što znači da su rezultati ispitanika znatno pomjereni prema nižim vrijednostima. Distribucija rezultata ispitanika na skalama zaštita potrošača, konkurencija i prodajno osoblje je leptokurtična, što govori da se rezultati ispitanika na skalama zaštita potrošača i prodajno osoblje grupišu u području znatno viših vrijednosti, a na skali konkurencija u području znatno nižih vrijednosti. Distribucija rezultata ispitanika na skalama asortiman i integrisane marketing komunikacije je platikurtična, što govori da postoji tendencija disperzije rezultata ispitanika na ovim skalama. Upravo ove skale direktno su vezane za uticaj novih tehnologija na kreiranje i upravljanje turističkim proizvodom i promocijom, a upućuju na to da ispitanici potpuno razlićito gledaju na važnost informacionih tehnologija na inoviranje sopstvenog marketinga. Pored toga, jasno je da ispitanici različito razumiju i poznaju koncept $\mathrm{E}$ - marketinga, da različito gledaju na njihov značaj, da koriste nesinhronizovano njegove različite instrumente.

Kada je riječ o institucijama, za ispitivanje iskustva i stavova vezanih implementaciju i doprinos informacionih tehnologija: zaštiti potrošača, konkurentskoj poziciji, asortimanu, saradnju i dostupnostu institucija međusobno i sa preduzećima, uticajima i saradnji stanovništva i institucija na turizam, stanju integrisanih marketing komu- nikacija te stanju zaposlenih u turizmu, konstruisana je i korištena skala Spoljni i unutrašnji elementi marketinga. Skala se sastoji od pedeset i tri stavke odnosno sedam subskala. Skala procjene i konačan skor formulisani su isto kao i za preduzeća. Od trideset i dva ispitanika dobijeno je $100 \%$ odgovora, dakle na sva pitanja su odgovorili svi ispitanici. Sve subskle pokazale su zadovoljavajuću pouzdanost tipa unutrašnje konzistencije. Kronbah alfa pokazuje sljedeće vrijednosti: 1 . Subskala zaštita potrošača alfa $=.71,2$. Subskala konkurencija alfa $=.51,3$. Subskala asortiman alfa $=.73,4$. Subskala saradnja i dostupnost alfa $=.60,5$. Subskala stanovništvo i institucije alfa $=.80,6$. Subskala integrisane marketing komunikacije alfa $=.89$ i 7. Subskala zaposleni u turizmu alfa $=.82$. Distribucija rezultata po skalama je predstavljena u Tabeli 2. redom kojim su ovdje navedene, gdje je Subskala zaštita potrošača označena kao 1.S, subskala konkurencija označena u tabeli kao 2.S i tako sve do subskale zaposleni u turizmu koja je označena kao 7.S.

Tabela 2 Mjere centralne tendencije, mjere varijabilnosti, mjere oblika distribucije i vrijednosti testiranja normalnosti distribucije

\begin{tabular}{|c|c|c|c|c|c|c|c|c|}
\hline $\mathrm{M}$ & $\mathrm{N}$ & $\mathrm{SD}$ & $\mathrm{Min}$ & $\mathrm{Max}$ & Skewen & Kurt. & K-Zz & Sig. \\
\hline 1. S 32 & 4.1 & .58 & 3 & 4.67 & -.567 & -.907 & .186 & .007 \\
\hline 2. S 32 & 3.57 & .49 & 4.5 & 1.67 & .634 & -.709 & .215 & .001 \\
\hline 3. S 32 & 3.15 & .75 & 2 & 4.67 & .234 & -.781 & .111 & .200 \\
\hline 4. S 32 & 3.63 & .54 & 2.43 & 4.43 & -.230 & -.272 & .140 & .116 \\
\hline 5. S 32 & 3.46 & .62 & 1.5 & 4.67 & -.940 & 2.074 & .164 & .029 \\
\hline 6. S 32 & 3.31 & .58 & 2.19 & 4.19 & -.326 & -.760 & .142 & .098 \\
\hline 7. S 32 & 4.42 & .54 & 3.33 & 5 & -.669 & -.754 & .178 & .011 \\
\hline
\end{tabular}

Dobijene distribucije rezultata ispitanika na skalama asortiman, saradnja i dostupnost i integrisane marketing komunikcije ne odstupaju značajno od normalne distribucije, dok dobijene distribucije rezultata ispitanika na skalama zaštita potrošača, konkurencija, stanovništvo i institucije i zaposleni u turizmu značajno odstupaju od normalne distribucije što potvrđuju rezultati Kolmogorov-Smirnovog testa (tabela 2.). Dobijene distribucije rezultata ispitanika na skalama zaštita potrošača, stanovništvo i institucije i zaposleni u turizmu su znatno negativno asimetrične, što znači da su rezultati ispitanika znatno pomjereni prema višim vrijednostima, dok je na skali konkurencija znatno pozitivno asimetrična, što znači da su rezultati ispitanika na ovoj skali znatno pomjereni prema nižim vrijednostima. Distribucija rezultata ispitanika na skali stanovništvo i institucije je leptokurtična, što govori da se rezultati ispitanika na ovoj skali grupišu u području znatno viših vrijednosti, dok je distribucija rezultata ispitanika na skalama zaštita potrošača, konkurencija i zaposleni u turizmu platikurtična, što govori da postoji tendencija disperzije rezultata ispitanika na ovim skalama. Dodatnom analizom može se još zaključiti i da je najniža aritmetička sredina svih odgovora na skali integrisane marketing komunikacije i iznosi 3.31, dok je suma najnižih vrijednosti na ovoj 
skali 2.19. Ovakvi rezultati mogu uputiti na zaključak da stanje novih tehnologija u upravljanju marketingom od strane institucija turizma, često nije na zadovoljavajućem nivou, te se ne može govoriti o konceptu $\mathrm{E}$ - marketinga. Istina, suma najviših vrijednosti iznosi 4.19, ali na ukupnu sliku utiču oni koji ovom procesu ne pristupaju na zadovoljavajući način. Iako je na gotovo svim skalama suma najnižih vrijednosti niska, treba spomenuti skalu saradnja i dostupnost gdje je suma najnižih vrijednosti 2.43 , a tiče se aktivnosti na koje turističke institucije imaju direktan uticaj te mogu aktivno inicirati poboljšanje stanja. Suma najnižih vrijednosti 1.5 i najviših 4.67 na skali stanovništvo i institucije upućuje na različito gledanje na ulogu i uticaj stanovništva na stanje prihvaćenosti informacionih tehologija od strane nadležnih institucija.

Kako bi se utvrdilo da li određeni elementi koji su ispitivani u institucijama i preduzećima turizma BIH imaju direktan uticaj na poboljšanje stanja po pitanju implementacije informacionih tehnologija u marketing turizma ove destinacije, što bi se direktno odrazilo na cjelukupan sistem turizma, urađena je regresiona analiza. Kao preduslov za primjenu regresione analize, urađena je korelacija. Kada su u pitanju institucije analiziran je odnos tj. postavljena korelacija informacionih tehnologija sa saradnjom i dostupnošću, tj. analizirano je u kojoj mjeri dosljedna primjena informacionih tehnologija može uticati na efikasnost saradnje institucija međusobno, institucija sa preduzećima, dostupnost i otvorenost institucija prema turistima (dostupnost promotivnih materijala, besplatni promotivni materijali i sl.), saradnjom sa rezidentima, saradnjom sa međunarodnim institucijama i sl.. Regresionom analizom je utvđeno da su informacione tehnologije u vrlo visokoj pozitivnoj korelaciji sa saradnjom i dostupnosti $(r=.645$; $\mathrm{p}<.01$ ), Pored toga, regresionom analizom utvđeno je da kao direktni prediktori informacionim tehnologijama doprinose saradnja i dostupnost (Beta $=.548 ; \mathrm{p}=.030)$. Time se dokazuje da je u novoj ekonomiji i $\mathrm{E}$ - marketingu uspješna saradnja i dostupnost neodvojiva od informacionih tehnologija tj. što bude više rastao interes za saradnjom, rašće i značaj informacionih tehnologija. I obrnuto, što bude značajnija implementacija ovih tehnologija jačaće stepen koordinacije između svih učesnika turističke privrede u BIH što će se direktno odraziti na razvoj novog marketing koncepta, a samim tim i pozicije na tržištu. Kada su u pitanju preduzeća analizirano je koliko informacione tehnologije preduzeća: mogu doprinijeti radu institucija turizma i međusobnoj saradnji; mogu doprinijeti razvoju savremenih koncepata marketinga i nivou usluge; koliko mogu uticati na efikasnost prodajnog osoblja. Dokazano je da su informacione tehnologije u visokoj pozitivnoj korelaciji sa marketingom i nivoom usluge $(\mathrm{r}=.474 ; \mathrm{p}<.01) \mathrm{i}$ prodajnim osobljem $(\mathrm{r}=.414 ; \mathrm{p}<.01)$, te korelaciji srednje visine sa radom institucija turizma i saradnjom $(\mathrm{r}=.344$; $\mathrm{p}<.05$ ), što je logično ako se uzme u obzir da inicijatori ove aktivnosti trebaju biti institucije turizma i da preduzeća ne mogu direktno uticati na njihov rad, već samo na međusobni odnos. Regresiona analiza pokazala je da kao najznačajniji direktni prediktor informacionim tehnologijama preduzeća doprinosi prodajno osoblje (Beta $=.307$; $\mathrm{p}=.035)$, iz čega se može zaključiti da je prvi korak ulaska na novo tržište, korak koji trebaju napraviti svi zaposleni u turističkim preduzećima prihvatajući suštinski novi način razmišljanja, što će se direktno odraziti na sve ostale elemente.

\section{ZAKLJUČAK}

$\mathrm{Na}$ bazi prethodnih rezultata istraživanja i teorijskog okvira, može se zaključiti da informacione tehnologije jesu veoma važan faktor formulisanja i realizacije marketing strategija na turističkom tržištu. Ipak, posmatrana destinacija ne implementira dovoljno njihove mogućnosti, ili ih bolje rečeno, ne razumije i ne poznaje dovoljno. Kada je riječ o rezultatima ispitivanja u preduzećima, jasno je da na većini subskala postoji ili disperzija rezultata što govori o različitim pogledima i neusaglašenosti, ili su rezultati pomjereni ka nižim vrijednostima, što govori o neshvatanju značaja. Slična situacija je i kada je riječ o institucijama. Ovdje posebno treba naglasiti prilično loše rezultate na subskali integrisane marketing komunikacije, gdje srednja vrijednost jedva prelazi 3, dok je suma najnižih vrijednosti 2,19 . Iz toga je jasno da se prednosti novih tehnologija ne koriste u dovoljnoj mjeri ni u promociji, a kamoli u istraživanju tržišta i nekim drugim elementima marketinga. Posmatrano tako pojedinačno, važno je reći da rezultati pokazuju da Institucije jedino pridaju značaj informacionim tehnologijama kada je riječ o promovisanju putem Interneta, gdje je srednja ocjena preko četiri. Sa druge strane direktom marketingu i istraživanju tržišta daju srednju ocjenu, koja je jedva iznad vrijednosti dva. Što upuće na to da dovoljno ne poznaju ove segmente marketinga i doprinose koje im mogu donijeti informacione tehnologije, a kamoli da ih primjenjuju. Situacija je gotovo identična i kada je riječ o preduzećima. Pored toga regresiona analiza je pokazala da, kada je riječ o institucijama, informacione tehnologije mogu imati dominantan uticaj na saradnju, dostupnost i koordinaciju svih učesnika u pružanju turističke usluge. Kada je riječ o preduzećima, ona je pokazala da je najvažnije prihvatanje informacionih tehnologija kao sastavnog dijela marketinga od strane zaposlenih, te da će se one na taj način direktno odraziti na stanje marketinga i nivoa usluge. Sve ovo, kao i primjeri razvijenih turističkih destinacija, koje svoje djelovanje na tržištu i svoju marketing strategiju ne mogu zamisliti brz informacionih tehnologija kao sastavnog dijela, upućuje na zaključak da će destinacije poput Bosne i Hercegovine morati veoma brzo učiti o novim tehnologijama i implementirati ih u svaki segment marketinga. Sasvim je jasno da uspješna pozicija na turističkom tržištu 21. vijeka zavisi i od prihvatanja tekovina i znanja 21. vijeka. U tom smislu i turizam nije izuzetak. E - marketing zasnovan na novim tehnologijama, jedno je od najvažnijih obilježja turizma novog doba. Savremeni potrošač traži savremene marketing koncepte, zasnovane na novim tehnologijama.

\section{LITERATURA}

[1] C. Longhi (2008), Usages of the Internet and E-Tourism: Towards a New power of Brand Web sites to BUILD AND Expand Brands, ESOMAR, Montreal. 
[2] Kotler, P. and K. Keller (2006), Merketing menadžment: 12 izdanje, Data Status, Beograd.

[3] B. Tihi (2003), Istraživanje marketinga, Ekonomski Fakulteta, Sarajevo.

[4] Avraham, E. and E. Ketter (2008), Media strategies marketing places in crisis, Elsevier.
[5] Chaffery, D., Mayer, R., Johnston, K., and F. Ellis Chadwich (2006), Internet Merketing Strategy Implementation and Practice: 3rd edition, Financial Times Prentice Hall, Harlow.

[6] B. Zečević (2002), Informaciona tehnologija u upravljanju marketingom turističke deestinacije, doktorska disertacija, Ekonomski fakultet, Beograd.

\section{THE EFFECT OF INFORMATION TECHNOLOGY ON MARKETING IN TOURISM OF BOSNIA AND HERZEGOVINA}

\section{Abstract:}

The paper entitled „The effect of information technology on marketing in tourism of Bosnia and Herzegovina" analyzes the implementation of information technology in tourism of a specific tourist destination. The paper clearly shows how important new technologies are for all aspects of tourism marketing, whereupon all aspects actually refer to activities such as, market research, built of marketing strategies and finally, integrated marketing communications itself. Through research of institutions and companies involved in tourism business in Bosnia and Herzegovina, carried out by a testing method, this paper offers a discovery that managers of institutions and companies in tourism, of a chosen destination, pay attention to the benefits of information technologies and to which extent they are implemented in tourism of Bosnia and Herzegovina. Based on the results of the mentioned research and theory in this field, the guidelines for its more effective implementation are finally derived.

\section{Key words:}

marketing in tourism, implementation of information technology, tourist destination, Bosnia and Herzegovina 